\title{
Doppler Ultrasonography of Ocular Blood Flow in Non- glaucoma versus Primary Open Angle Glaucoma Subjects at University of Nigeria Teaching Hospital, Enugu
}

\section{Stella Ngozi Onwubiko}

University of Nigeria Teaching Hospital

Nkiru Zuada Nwachukwu ( $\nabla$ nkiru.nwachukwu@unn.edu.ng )

University of Nigeria Teaching Hospital

Ogbonna Markson Nkwegu

Alex Ekwueme Federal University Teaching Hospital Abakaliki

Ifeoma Arinze

University of Nigeria Teaching Hospital

Ernest Nnaemeka Onwasigwe

University of Nigeria Teaching Hospital

Rich Enujioke Umeh

University of Nigeria Teaching Hospital

\section{Research Article}

Keywords: Ocular blood flow, Glaucoma, Doppler indices, Black population.

Posted Date: March 7th, 2022

DOI: https://doi.org/10.21203/rs.3.rs-1265588/v1

License: (c) (i) This work is licensed under a Creative Commons Attribution 4.0 International License. Read Full License 


\section{Abstract}

Purpose: To evaluate and compare the ocular blood flow in non-glaucoma versus primary open-angle glaucoma (POAG) subjects attending the ophthalmic clinic of University of Nigeria Teaching Hospital (UNTH) Enugu using Doppler ultrasonography.

Methods: A cross-sectional comparative study was adopted. Fifty-Eight POAG and 58 non-glaucoma subjects were recruited. Information on their socio-demographic and clinical profiles was obtained via an interviewer-administered questionnaire. Ocular Doppler Imaging was performed on all the Subjects. Peak systolic volume, End diastolic volume, mean flow velocity and Resistive Index (RI) of the central retinal artery and ophthalmic artery were recorded. Data were analysed using the SPSS version 21. Person correlation was used to determine the relationship between the Doppler indices and demographic and clinical variables. The level of significance was at $p<0.05$.

Results: The subjects were mainly males, 71(61.7\%), with an age range of 40 to 79 years. The POAG Subjects lived with glaucoma for $5.57 \pm 4.2$ years, and mainly on medical treatment $52(89.7 \%)$ with beta-blockers and prostaglandin analogues. The RI was significantly higher $(p=0.01)$ in POAG subjects. A significant positive relationship $(P=0.014)$ was observed between RI and intraocular pressure (IOP) of the POAG subjects.

Conclusion: In POAG subjects, RI was significantly higher; as the IOP increased there was an increase in RI translating to a sub-optimal ocular blood flow. Interventions aimed at modifying the RI would therefore be synergistic with IOP lowering measures. Additionally, RI assessment may offer a new target for glaucoma case finding.

\section{Introduction}

Globally, glaucoma is the leading cause of avoidable, irreversible blindness, affecting about 64.3 million people, with a prevalence of $3.54 \%$ in those aged between $40-80$ years [1]. The prevalence of POAG is highest in Africa (4.2\%) [1]. In Nigeria, it accounted for $16.7 \%$ of blindness and is the leading cause of functional low vision [2].

The mechanisms underlying the development and progression of glaucoma remain uncertain [3]. Several risk factors have been implicated with IOP being the only modifiable risk factor. However, it has become increasingly clear that blood supply compromise also plays a significant role in glaucomatous optic neuropathy [4]. Despite the various current approaches to glaucoma treatment aimed at maintaining target intraocular pressure, there are still documented evidence of progressive optic disc cupping and visual field loss within a normal range of intraocular pressure [5]. Consequently, management of glaucoma beyond IOP control has been proposed [6].

Retinal blood flow assessment using Doppler ultrasonography has been investigated by several studies [7-12]. Compromised ocular blood flow was observed in eyes with POAG in Canada [7], Europe [8, 9], Asia [10], and elsewhere in Nigeria $[11,12]$. However, the few Nigerian studies $[11,12]$ were among the south-western population. None has been conducted in the South-east, which harbours predominantly the ethnic Igbos with the highest prevalence $(7.77 \%)$ of glaucoma in Nigeria [13] and a risk factor for glaucoma blindness [14].

This study, therefore, sought to investigate the possible variations in the ocular blood flow to the optic nerve head in POAG and non-glaucomatous subjects among Igbo ethnic groups within Southeast Nigeria. It is hoped that findings from this study would contribute to the management guideline for glaucoma and may offer a new target for glaucoma case finding and treatment in the study area and elsewhere with similar settings.

Study Area- The study was conducted at Ophthalmology and Radiology Departments, University of Nigeria Teaching Hospital (UNTH), Ituku Ozalla, Enugu State, South-Eastern Nigeria. UNTH serve mainly the Enugu State population and the other South-Eastern States, as well as South-South Nigeria and beyond. 
Study population- This comprised POAG and non-glaucoma subjects, who attended the Eye clinic at UNTH from January to June 2019.

Study design- This was a cross-sectional, descriptive, prospective and comparative study involving 58 consecutive consenting POAG patients and 58 non-glaucoma subjects, who met with the inclusion criteria. Information on their sociodemographic and clinical profiles was obtained via an interviewer-administered questionnaire.

Inclusion criteria for POAG subjects- Patients who are 40 years and above, clinically diagnosed with POAG by the glaucoma specialists and with transparent ocular media.

Inclusion criteria for non-glaucoma subjects- Patients who are 40 years and above, with simple refractive errors or presbyopia with transparent ocular media and no other ocular pathology who consented to participation.

Exclusion criteria- patients with ocular congenital abnormalities, retinopathies, on systemic medication affecting blood flow, with cataracts or corneal opacity precluding posterior segment assessment. Patients who did not give consent, aged less than 40 years. Patients with cardiovascular diseases such as carotid occlusive disorders, atherosclerosis, hypertension, Diabetes mellitus. Glaucoma suspects and all patients clinically diagnosed with secondary glaucoma and angle-closure glaucoma.

\section{Minimum Sample Size Determination}

The sample size for each arm of this study was determined with the following formula [15]

$S=\backslash$ frac $\left.\left\{2\{\otimes\}^{\wedge}\{2\}\{(\text { Z Ibeta }+ \text { Zlalpha } 2)\}^{\wedge}\{2\}\right\}\left\{\left(\{d\}_{-}\{1\}-\{d\}_{-}\{2\}\right)\right\}^{\wedge}\{2\}\right\}$

$\{\text { Difference }\}^{\wedge}\{2\}=\left\{\left(\{\mathrm{d}\}_{-}\{1\}-\{\mathrm{d}\}_{-}\{2\}\right)\right\}^{\wedge}\{2\}$

$\mathrm{S}=$ Minimum sample size of each of the study groups.

$a=$ Probability of making type one error

$\beta=$ Probability of making type two error

Za2 = level of significance of type one error probability; determined from a statistical table based on the value of the level of significance $\alpha$; for this study was set at 0.05 , the ninety-five (95\%) confidence interval $=1.96$ for a two-tailed test(standard normal deviate)

$Z \beta=$ type two error probability corresponding to standard normal deviate for a stated power of the study to detect a significant difference.

For this study, a power of 90 was used therefore $Z \beta=1.28 \sigma \nabla 2$, Standard deviation of the outcome variable in glaucoma subjects. $d 1-d 2$ = difference in the means of glaucoma and normal subjects. 21

Adding $10 \%$ attrition (5.22), the minimum sample size $=57.39$.

Therefore, a total of 116 persons comprising 58 glaucoma and 58 normal subjects were recruited as the study participants.

\section{Sampling technique}

To obtain the required sample size, consecutive enrolment was used. All consecutive, consenting patients who met the inclusion criteria were enrolled on the study until the estimated sample size was obtained for the two groups. 
Study procedure: subjects diagnosed with POAG were evaluated for eligibility and recruited into the study, as well as the non-glaucoma subjects. After obtaining consent, the pre-tested, structured questionnaire comprising of two sections:socio-demographic and clinical sections was administered by the researchers. Thereafter, each subject had the following examinations:

Intraocular pressure was measured using a Goldman applanation tonometer. The prism was disinfected with isopropyl alcohol $70 \%$ rinsed in sterile water and wiped dry with a clean swab. After checking the graduation and setting the calibrated dial to $10 \mathrm{mmHg}$, the patient was seated comfortably at the slit-lamp, a local anaesthetic drop was instilled in the lower fornix of the conjunctiva. After a while, the tear-film was stained with a fluorescein strip. With the patient looking straight ahead, the prism was gradually placed to rest gently on the centre of the patient's cornea, the calibrated dial on the tonometer was turned clockwise until the inner edges of the semi-circles in the prism head were seen to touch. The reading on the dial was then noted and recorded.

Ocular Doppler ultrasonography of the ophthalmic and central retinal arteries was done using the Nemio XG ultrasound machine (Model no.SSA-580A) with an $11 \mathrm{MHz}$ curvilinear transducer and Doppler facility at the Radiology department. The subject was placed in a supine position on a couch, with gaze directed at a marked spot on the ceiling. With the eyelids closed, and the gaze maintained, the power level of the ultrasound machine was set at $10 \%$ which is equivalent to 16- $1 \mathrm{mw} / \mathrm{cm} 2$, the safety limit. The ultrasound transducer was applied to the closed eyelids using a coupling gel (K-Y jelly). The right eye of the subjects in both groups was used for the study.

Greyscale imaging was performed routinely in every subject to obtain an overview of the orbital anatomy. Axial and sagittal planes were included during the real-time scanning. Pulsed Doppler ultrasonography was performed with the gain optimized such that colour would be seen within the vessels without any colour artefacts, allowing the detection of low velocities. The sample volume depth was set at $40 \mathrm{~mm}$ when imaging the ophthalmic artery (OA). The Doppler sample gate of $2 \mathrm{~mm}$ was placed at the centre of the detected vessels to image the spectral pattern. As orbital vessels were frequently parallel to the ultrasound beam, an angle correction of 600 was used when needed and the colour box steering would sometimes be required to attain this. A low wall filter setting was used. To examine the OA, the sample volume was oriented nasally and superior to the optic nerve, as the OA is lateral to and abuts the visible hypo reflective stripe representing the nerve, while the central retinal artery (CRA) was imaged in the shadow of the optic nerve, the sample was placed about $3 \mathrm{~mm}$ behind the surface of the optic disc.

The Peak Systolic Velocity (PSV) and End Diastolic Velocity (EDV) values were obtained by taking the velocity reading at the peak of the spectral wave pattern and that at the wave trough, respectively. Three readings of each artery were obtained and the average is taken to minimize intra observer error.

\section{Doppler Ultrasonography Indices}

- Peak systolic velocity (PSV) is the maximum peak systolic velocity (PSV) normal $=32.35 \pm 10.41$ for OA and $9.4 \pm 2.2$ for CRA.

- Mean flow velocity (MFV) is the mean of the peak frequency, peaks envelope which outlines all the frequency peaks forming a single signal in one cardiac cycle, normal is $16.35 \pm 2.94$

- End Diastolic flow velocity (EDV) is the minimum flow velocity at the end of the diastolic phase before the next cardiac cycle, $($ EDV) normal $=8.19 \pm 3.64$ for OA and $2.0-4.0$ for CRA.

- Resistive Index (RI) is calculated as the Porcelouts [16] ratio for OA and CRA as (PSV-EDV)/PSV and normal is 0.73. 
Data management - Data was coded and analysed using the statistical package for social sciences version 20 . The descriptive statistics - frequency, percentage, mean, range and standard deviation were used to summarise the data. Means of continuous variables were compared using a student t-test between the two groups. Pearson correlation was used to test the relationships between the Doppler indices and IOP of the two groups - POAG and non-glaucoma subjects, as well as between indices and demographic variables. A p-value $<0.05$ was regarded as statistically significant.

\section{Results}

The participants have mainly married males, civil servants and traders, with at least primary school education within the age range of 40 to 79 years. There was no significant difference in the socio-demography of the two groups, Table 1. 
Table 1

Socio-demographic characteristics of the non-glaucoma $(\mathrm{N})$ and glaucoma $(\mathrm{G})$

\begin{tabular}{|c|c|c|c|c|c|c|}
\hline Demographic characteristics & $\mathrm{N}=58$ & $G=58$ & Total $=116$ & Chi-Square & df & P-value \\
\hline \multicolumn{7}{|l|}{ Age group } \\
\hline $40-49 y r s$ & $18(31.0)$ & $15(25.9)$ & $33(28.4)$ & 1.46 & 4 & 0.834 \\
\hline $50-59 y r s$ & $20(34.5)$ & $17(29.3)$ & 37 (31.9) & & & \\
\hline $60-69 y r s$ & $10(17.2)$ & $12(20.7)$ & $22(19.0)$ & & & \\
\hline $70-79 y r s$ & $10(17.2)$ & $14(24.1)$ & $24(20.7)$ & & & \\
\hline \multicolumn{7}{|l|}{ Gender } \\
\hline Male & $37(64.9)$ & $34(58.6)$ & $71(61.7)$ & 0.327 & 1 & 0.568 \\
\hline Female & $21(36.2)$ & $24(41.4)$ & $45(38.8)$ & & & \\
\hline \multicolumn{7}{|l|}{ Marital status } \\
\hline Single & $1(1.7)$ & $3(5.2)$ & $4(3.4)$ & 4.185 & 4 & 0.382 \\
\hline Married & $47(81.0)$ & $49(84.5)$ & $96(82.8)$ & & & \\
\hline Divorced & $5(8.6)$ & $1(1.7)$ & $6(5.2)$ & & & \\
\hline Separated & $1(1.7)$ & $2(3.4)$ & $3(2.6)$ & & & \\
\hline Widowed & $4(6.9)$ & $3(5.2)$ & $7(6.0)$ & & & \\
\hline \multicolumn{7}{|l|}{ Educational level } \\
\hline Primary & $19(32.8)$ & $17(29.3)$ & $36(31.0)$ & 2.731 & 3 & 0.435 \\
\hline Secondary & $12(20.7)$ & $15(25.9)$ & $27(23.3)$ & & & \\
\hline Tertiary & $9(15.5)$ & $14(24.1)$ & $23(19.8)$ & & & \\
\hline None & $18(31.0)$ & $12(20.7)$ & 30 (25.9) & & & \\
\hline \multicolumn{7}{|l|}{ Occupation } \\
\hline Civil servant & $15(25.9)$ & 15 (25.9) & 30 (25.9) & 5.687 & 7 & 0.577 \\
\hline Trading & $12(20.7)$ & $13(22.4)$ & $23(21.6)$ & & & \\
\hline Farming & $3(5.2)$ & $6(10.3)$ & $9(7.8)$ & & & \\
\hline Artisan & $4(6.9)$ & $6(10.3)$ & $10(8.6)$ & & & \\
\hline Unemployment & $1(1.7)$ & $3(5.2)$ & $4(3.4)$ & & & \\
\hline Driver & $5(8.6)$ & $2(3.4)$ & $7(6.0)$ & & & \\
\hline Retiree & $15(25.9)$ & 9 (15.5) & $24(20.7)$ & & & \\
\hline Housewife & $3(5.2)$ & $4(6.9)$ & $7(6.0)$ & & & \\
\hline
\end{tabular}

The POAG subjects lived with glaucoma for $5.57 \pm 4.2$ years and were mainly on medical treatment with beta-blockers and prostaglandin analogues, Table 2. 
Table 2

Ocular profile of the POAG patients

\begin{tabular}{|lll|}
\hline Ocular Profile & Frequency & Percentage \\
\hline Types of treatment & 52 & \\
\hline Medical & 6 & $10.3 \%$ \\
\hline Surgical & & \\
\hline Types of Surgical treatment & 6 & $5.2 \%$ \\
\hline Trabeculectomy & 0 & $0.0 \%$ \\
\hline Others & & \\
\hline *Drugs received & 54 & $61.4 \%$ \\
\hline Beta-blockers & 2 & $2.3 \%$ \\
\hline Alpha -2 agonist & 27 & $30.7 \%$ \\
\hline Prostaglandin analogues & 5 & $5.7 \%$ \\
\hline Systemic Carbonic anhydrase inhibitor & 5 & \\
\hline Years of living with Glaucoma & & $53.4 \%$ \\
\hline $0-5 y e a r s$ & 31 & $31.0 \%$ \\
\hline 6 - 10years & 18 & $12.1 \%$ \\
\hline $11-20$ years & 7 & \\
\hline *multiple responses. & & \\
\hline
\end{tabular}

The mean IOP in POAG subjects $(17.8 \pm 3.4 \mathrm{mmHg})$ was significantly higher than in non-glaucoma subjects (15.2 $\pm 3.3 \mathrm{mmHg}), p=0.000$.

The MFV and RI were observed to be significantly higher in POAG subjects while comparing the Doppler indices between the two groups, Table 3. There was no difference in PSV and EDV between the two groups, Table 3.

Table 3

Comparison of the Doppler Ultrasound Indices among the non-glaucoma $(\mathrm{N})$ and glaucoma $(\mathrm{G})$ subjects

\begin{tabular}{|c|c|c|c|c|}
\hline & G & $\mathbf{N}$ & & \\
\hline Doppler Indices & Mean \pm SD & Mean $\pm S D$ & $\mathrm{t}$ - value & P-value \\
\hline $\mathrm{PSV}(\mathrm{cm} / \mathrm{s})$ & $39.99 \pm 17.67$ & $36.56 \pm 14.98$ & -1.128 & 0.262 \\
\hline $\mathrm{EDV}(\mathrm{cm} / \mathrm{s})$ & $15.21 \pm 8.18$ & $15.82 \pm 8.95$ & 0.379 & 0.705 \\
\hline $\mathrm{MFV}(\mathrm{cm} / \mathrm{s})$ & $18.39 \pm 4.71$ & $15.09 \pm 2.53$ & 4.702 & $0.000 *$ \\
\hline $\mathrm{RI}(\mathrm{cm} / \mathrm{s})$ & $0.92 \pm 0.18$ & $0.85 \pm 0.110$ & -2.719 & $0.008 *$ \\
\hline
\end{tabular}

There was a significant positive relationship between the IOP and RI of the POAG participants $(P=0.014)$, which implied that as the IOP increases, there is an expected increase in the RI of the POAG subjects. Table 4. 
Table 4

Correlation between IOP and other Doppler indices of the two groups ( $\mathrm{N}=$ Non- glaucoma subjects, $\mathrm{G}=$ Glaucoma

\begin{tabular}{|llll|}
\hline & & N & G \\
\hline Parameters & Test & IOP & IOP \\
\hline PSV & Pearson Correlation & 0.037 & 0.042 \\
\hline & P-value & 0.785 & 0.756 \\
\hline EDV & N & 57 & 57 \\
\hline & Pearson Correlation & 0.076 & -0.1 \\
\hline MFV & P-value & 0.574 & 0.459 \\
& N & 57 & 57 \\
\hline & Pearson Correlation & -0.007 & 0.113 \\
\hline RI & P-value & 0.957 & 0.403 \\
& N & 57 & 57 \\
& Pearson Correlation & 0.14 & 0.322 \\
& P-value & 0.299 & $\mathbf{0 . 0 1 4}$ \\
\hline & N & 57 & 57 \\
\hline
\end{tabular}

There was no significant gender difference in the Doppler indices, IOP and BP between the two groups, table 5 and there was no significant relationship between age and all the variables in the Doppler indices, IOP and BP in both study groups, Table 6.

Table 5: Gender differences in IOP, Doppler indices and BP between the non-glaucoma $(\mathrm{N})$ and glaucoma (G) subjects

\begin{tabular}{|lllllllll|}
\hline \multicolumn{2}{r}{} & N & & & & G & & \\
\hline Parameters & Males & Females & T & $\begin{array}{l}\text { P- } \\
\text { value }\end{array}$ & Males & Females & $\begin{array}{c}\text { T } \\
\text { P- } \\
\text { value }\end{array}$ \\
\hline Average IOP & $15.50 \pm 3.31$ & $14.89 \pm 3.22$ & 0.688 & 0.49 & $18.35 \pm 3.80$ & $18.65 \pm 4.63$ & 2620. & 0.794 \\
\hline PSV (cm/s) & $40.32 \pm 18.85$ & $39.52 \pm 16.23$ & 0.168 & 0.867 & $39.48 \pm 14.58$ & $31.48 \pm 14.46$ & 2.051 & 0.05 \\
\hline EDV (cm/s) & $15.09 \pm 7.96$ & $15.40 \pm 8.64$ & -0.1444 & 0.886 & $16.68 \pm 8.90$ & $14.79 \pm 9.03$ & 0.763 & 0.449 \\
\hline PI (cm/s) & $2.73 \pm 1.37$ & $2.15 \pm 1.04$ & 1.744 & 0.087 & $2.33 \pm 0.96$ & $2.40 \pm 1.02$ & 0.258 & 0.797 \\
\hline MFV(cm/s) & $19.02 \pm 5.70$ & $17.51 \pm 2.64$ & 1.204 & 0.234 & $14.89 \pm 2.73$ & $15.37 \pm 2.17$ & 0.669 & 0.506 \\
\hline RI (cm/s) & $0.93 \pm 0.20$ & $0.91 \pm 0.13$ & 0.490 & 0.626 & $0.86 \pm 0.12$ & $0.82 \pm 0.09$ & 1.307 & 0.197 \\
\hline $\begin{array}{l}\text { Systolic BP } \\
\text { (mm/Hg) }\end{array}$ & $115.00 \pm 9.92$ & $113.33 \pm 11.67$ & 0.586 & 0.561 & $119.19 \pm 10.37$ & $121.00 \pm 8.52$ & 0.479 & 0.634 \\
\hline $\begin{array}{l}\text { Diastolic } \\
\text { BP(mm/Hg) }\end{array}$ & $71.06 \pm 6.45$ & $68.75 \pm 7.97$ & 1.173 & 0.247 & $75.14 \pm 8.37$ & $74.00 \pm 8.83$ & 0.973 & 0.335 \\
\hline Sys/Dia & $2.72 \pm 0.91$ & $2.75 \pm 1.03$ & -0.106 & 0.916 & $2.65 \pm 0.79$ & $2.45 \pm 0.68$ & 0.688 & 0.494 \\
\hline
\end{tabular}


Page $9 / 13$ 
Table 6

Correlation between Age and IOP, Doppler indices and BP of the nonglaucoma $(\mathrm{N})$ and glaucoma $(\mathrm{G})$ groups

\begin{tabular}{|c|c|c|c|}
\hline & & $\mathbf{N}$ & G \\
\hline Parameters & Test & Age (years) & Age (years) \\
\hline \multirow[t]{3}{*}{ Average IOP } & Pearson Correlation & -0.092 & -0.008 \\
\hline & P-Value & 0.495 & 0.951 \\
\hline & $\mathrm{N}$ & 57 & 57 \\
\hline \multirow[t]{3}{*}{ PSV(cm/s) } & Pearson Correlation & 0.057 & -0.154 \\
\hline & P-Value & 0.67 & 0.247 \\
\hline & $\mathrm{N}$ & 58 & 58 \\
\hline \multirow[t]{3}{*}{$\operatorname{EDV}(\mathrm{cm} / \mathrm{s})$} & Pearson Correlation & 0.066 & -0.118 \\
\hline & P-Value & 0.624 & 0.379 \\
\hline & $\mathrm{N}$ & 58 & 58 \\
\hline \multirow[t]{3}{*}{$\mathrm{Pl}(\mathrm{cm} / \mathrm{s})$} & Pearson Correlation & -0.081 & 0.049 \\
\hline & P-Value & 0.545 & 0.714 \\
\hline & $\mathrm{N}$ & 58 & 58 \\
\hline \multirow[t]{3}{*}{$\mathrm{MFV}(\mathrm{cm} / \mathrm{s})$} & Pearson Correlation & -0.22 & 0.1 \\
\hline & P-Value & 0.097 & 0.455 \\
\hline & $\mathrm{N}$ & 58 & 58 \\
\hline \multirow[t]{3}{*}{$\mathrm{RI}(\mathrm{cm} / \mathrm{s})$} & Pearson Correlation & 0.121 & 0.001 \\
\hline & P-Value & 0.366 & 0.995 \\
\hline & $\mathrm{N}$ & 58 & 58 \\
\hline \multirow[t]{3}{*}{ Systolic BP(mmHg) } & Pearson Correlation & 0.118 & 0.239 \\
\hline & P-Value & 0.379 & 0.071 \\
\hline & $\mathrm{N}$ & 58 & 58 \\
\hline \multirow[t]{3}{*}{ Diastolic BP(mmHg) } & Pearson Correlation & 0.043 & 0.148 \\
\hline & P-Value & 0.751 & 0.266 \\
\hline & $\mathrm{N}$ & 58 & 58 \\
\hline \multirow[t]{3}{*}{ Systolic/Diastolic } & Pearson Correlation & -0.08 & -0.02 \\
\hline & P-Value & 0.552 & 0.883 \\
\hline & $\mathrm{N}$ & 58 & 58 \\
\hline $\mathbf{N}=$ Non- glaucoma su & jects, $G=$ Glaucoma st & jects. & \\
\hline
\end{tabular}


The participants have mainly married males within the age range of 40 to 79 years. These demographic characteristics are similar to a Nigerian study [11]. Males from this study population sought eye care more than females, probably the male folk seems to be more economically empowered than females in the study environment. Appropriate public health measures and universal access to eye care should therefore be promoted by the stakeholders.

The POAG subjects lived with glaucoma for $5.57 \pm 4.2 S D$ years, and were mainly on medical treatment, with their mean IOP significantly higher than in non-glaucoma subjects. This ocular profile is similar to a study in Nigeria [11] but contrasts with the Canadian study [3] which studied the angle-closure glaucoma subjects as well.

In this study, while comparing the Doppler indices, there was no difference in PSV and EDV between the two groups. This contrasts with the reports of the south-western Nigerian studies [11,12], where these indices were significantly reduced in the POAG group. However, the RI which was significantly higher in POAG subjects, in this study agreed with their findings $[11,12]$ and other varied populations across the globe, North America [7], Europe [9], and Asia. [10].

The Japanese study [17] found no difference in RI, probably because their study subjects were POAG and normal pressure glaucoma patients without a control group. The higher RI in POAG subjects implies sub-optimal blood flow to the optic nerve. The fact that RI is a ratio [16], an absolute value derived from PSV and EDV independent of the Doppler angle makes it a more useful index for comparison among studies.

There was a significant positive relationship between the IOP and RI of the POAG participants, in this study. This was similar to the observations made elsewhere in Nigeria [11, 12], and Europe [18], which suggests direct impedance to the ocular blood flow by elevated IOP. In consonance, Singh et al [19] reported that when target pressure was achieved, the reduced ocular blood flow parameters in POAG subjects became similar to those of the non-glaucomatous eyes suggesting improved ocular blood flow as a function of reduced IOP.

In this study, there was no age and gender difference or relationship with the Doppler indices of the groups. Comparatively, indices suggestive of reduced ocular blood flow in males would have been expected in this study population, where the male gender is a documented risk factor for glaucoma blindness [14]. However, other studies did not explore this finding, precluding a robust discussion. Future studies should therefore investigate the influence of these variables on ocular blood flow.

\section{Conclusion}

The RI of the central retinal artery was significantly higher in POAG subjects and a significant positive relationship was observed between their RI and IOP. As the IOP increased there was an increase in RI translating to a sub-optimal ocular blood flow. Interventions aimed at modifying the RI would therefore, be synergistic with IOP lowering measures. Additionally, RI assessment may offer a new target for glaucoma case finding.

\section{Declarations}

Funding: This study was self-sponsored.

\section{Compliance with Ethical Standards}

Ethics approval: Ethical approval for the study was obtained from the Health Research and Ethics Committee of the University of Nigeria Teaching Hospital, Ituku-Ozalla, Enugu (NHREC/05/01/2008B-FWA00002458-1RB00002323).

Research involving human participants: All procedures were performed in line with 1964 Helsinki Declaration for human subjects (as amended). 
Conflict of Interest: There is no conflict of interest (financial or otherwise) among the authors.

Informed consent: Written informed consent was obtained from each participant in accordance with the tenets of Helsinki declaration for human studies. Participation in the study was voluntary and at no cost to the subjects.

Author contribution: Markson Ogbonna Nkwegu (MON); Stella Ngozi Onwubiko (SNO); Nkiru Zuada Nwachukwu (NZN); Ifeoma C. Arinze (ICA); C.U.Ibewike (CUI), Ernest Nnaemeka Onwasigwe (ENO), Rich E. Umeh (REU).

MON, SNO and NZN designed the study. The clinical study was performed by MON, ICA and CUI. The manuscript was written by SNO and NZN and edited by ENO and REU. Statistical analysis was done by MON, ICA and ENO.

Consent to publish: All the authors agreed that this manuscript should be submitted to your journal for publication.

Acknowledgement: The authors wish to thank the management of University of Nigeria Teaching Hospital for allowing us the hospital facilities.

\section{References}

1. Tham YC, Hons B, Li X, Wong TY, Quigley HA, Aung T, et al. Global Prevalence of Glaucoma and Projections of Glaucoma Burden through 2040 A Systematic Review and Meta-Analysis. AAO. 2014;121:2081-2090.

2. Abdull MM, Sivasubramaniam S et al. Nigeria National Blindness and Visual Impairment Study Group. Causes of blindness and visual impairment in Nigeria: The Nigeria national blindness and visual impairment survey. Invest Ophthalmol Vis Sci. 2009;50:4114-4120.

3. Cherecheanu AP, Garhofer G, Schmidl D, Werkmeister R, Schmetterer L. Ocular perfusion pressure and ocular blood flow in glaucoma. Curr Opin Pharmacol. 2013;13(1):36-42.

4. Grieshaber MC, Flammer J. Blood flow in glaucoma, Curr Opin Ophthalmol. 2005;16(2):79-83.

5. Rath EZ, Shin DH, Kim C, Tsai CS, Zeiter JH, Hong YJ. Relationship between optic disc cupping change and intraocular pressure control in adult glaucoma patients. Graefes Arch Clin Exp Ophthalmol. 1996;234(7):434-43

6. 6. Claude FB, Louis BC, Jay C, Lucile L et al. Managing Glaucoma: Beyond Intraocular Pressure, Review of Ophthalmology Online 2016;16(16):

7. Rojanapongpun P, DranceSM, Morrison BJ. Ophthalmic Artery flow velocity in glaucomatous and normal subjects. British Journal of Ophthalmology. 1993;77(1):25-29.

8. Stalmanns I, Vandewalle E, Anderson DR, Costa VP, Frenkel RE, et al. Use of Colour Doppler imaging in ocular blood flow research. Acta Ophthalmologica. 2011;89:609-630.

9. Akarsu C, Bilgili MY. Colour Doppler imaging in ocular hypertension and open-angle glaucoma. Graefes Arch Clin Exp Ophthalmol. 2004;242:125-129

10. Sharma NC, Bangiya D. Comparative study of ocular blood flow parameters by colour Doppler imaging in the healthy and glaucomatous eye. Indian J Radiol Imaging. 2006;16:679-689

11. Odunlami OA, Ayoola O, Onakpoya OH, Adetiloye VA, Arogundade R. Ocular blood flow velocity in primary open-angle glaucoma - A tropical African population study. Middle East Afr J Ophthalmol 2013;20:174-178.

12. Eniola MA, Adeyomoye AAO, Musa KO, Ishola AAS, Olatunji OO. Ophthalmic artery and central retinal artery Doppler patterns in primary open-angle glaucoma patients at the Lagos University Teaching Hospital, Nigeria. J West Afr Coll Surg.2018;8(3): 1-21.

13. Abdull MM, Sivasubramaniam S et al. Nigeria National Blindness and Visual Impairment Study Group. Causes of blindness and visual impairment in Nigeria: The Nigeria national blindness and visual impairment survey. Invest Ophthalmol Vis Sci. 2009;50:4114-4120.

Page 12/13 
14. Kyari F, Wormald R, Murthy GV, Evans JR, Gilbert CE, et al. Nigeria National Blindness and Visual Impairment Study Group. Ethnicity and Deprivation are Associated With Blindness Among Adults With Primary Glaucoma in Nigeria: Results From the Nigeria National Blindness and Visual Impairment Survey. J Glaucoma. 2016;25(10):e861-e872.

15. Campbell M.J, Machin DC, Comparison of means: In; medical statistics; common-sense approach, 2nd edition England: John Willey and Ltd. West Sussex; 1990.

16. Landre Porcelouts. Arterial Resistive Index calculation. Available from Wikipedia, the free encyclopedia, HTTP //en.Wilipedia.org /Wiki / Arterial Resistivity Index (Accessed 5th July 2019)

17. Yoshio Y, Fukuko H. Comparison of the flow velocity of the ophthalmic artery between primary open-angle glaucoma and normal-tension glaucoma. British Journal of Ophthalmology. 1995;79:732-734

18. Butt Z, O' Brien C, Mckillop G, Aspinall P, Allan P. Colour Doppler imaging in untreated high and normal pressure openangle glaucoma. Invest Ophthalmol Vis. Sci, 1997;38:690-696

19. Singh M D, Sharma C, Prasad A. A colour Doppler study of retrobulbar blood flow parameters in patients of primary open-angle glaucoma. Indian J Clin Exp Ophthalmol 2015;1(2):84-90 